tigación dentro de los estudios de la historia de la traducción y la traductología, muy necesario por profundizar en obras, autores, contextos y diversos factores que permanecían inexplorados hasta el momento. Traducir a los clásicos: entornos $y$ transformaciones es una obra que resulta de interés tanto para estudiantes e investigadores académicos del ámbito de la traducción, como para el público interesado o relacionado con el sector editorial.

\title{
New Approaches to Translation, Conflict and Memory. Narratives of the Spanish Civil War and the Dictatorship
}

LUCÍA PINTADO GUTIÉRREZ \& ALICIA CASTILLO VILLANUEVA (EDS.)

Colección Palgrave Studies in Languages at War, Cham: Palgrave Macmillan.

Mohamed Hatem Faris

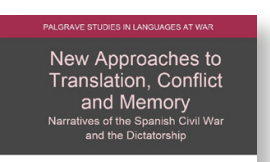

El papel de la traducción y la interpretación en una España asolada por la guerra civil y posterior dictadura continúa siendo un campo de investigación cada vez más atractivo para la comunidad científica debido a su inmensa capacidad de ayudarnos a entender mejor el conflicto y el periodo de represión política. En sus 243 páginas, la obra New Approaches to Translation, Conflict and Memory, Narratives of the Spanish Civil War and the Dictatorship reúne una antología de diez estudios, fraccionada en cinco partes, que profundizan en el papel que desempeñaron fenómenos relacionados con la traducción durante un momento histórico tan influyente para el devenir del país. En el ensayo introductorio,

«Emerging Trends in Reassessing Translation, Conflict, and Memory» (pp. 3-20), Castillo Villanueva y Pintado Gutiérrez abren la primera parte de una pormenorizada investigación sobre la influencia de la traducción en el contexto de la Guerra Civil, pues a día de hoy se echan en falta análisis significativos sobre la relación existente entre traducción, conflicto y estudios de la memoria. Con el inicio del libro, las editoras del mismo defienden la tesis de que la traducción funciona como el nexo de unión entre los otros dos ámbitos. Así, en contextos bélicos, es considerable la estrecha relación entre una traducción fiel y una interpretación adaptada al compromiso e influencia política del momento. En ambientes de conflicto social y político, el discurso se ofrece notablemente vinculado al poder.

En el caso de España, la censura ejercida por la Dictadura seguida por el Pacto de Olvido que llegó con la Transición y los primeros años de democracia, provocaron una ausencia que, tiempo después, estallaría en la España contemporánea como forma de justicia a ese pasado silenciado a tantos niveles. A través del estudio de las fuentes de archivo se pueden obtener las restricciones a las que se sometieron los traductores de la época y, a partir de ellas, elaborar nuevos discursos que permiten vislumbrar una realidad más nítida. La ideología predominante en la sociedad fuerza una reescritura por parte de los traductores, una manipulación literaria que se ajusta a las normas sociales y al poder establecido, tal y como sucedió con el régimen de Franco. Mediante el estudio del papel desempeñado por los traductores se puede analizar la perspectiva desde la que se enfocó el conflicto en España y fuera de ella. Por tanto, el afán actual de honrar la memoria republicana ha instado al estudio de la memoria individual y colectiva a través de la reescritura de la historia desde un nuevo prisma. 
En la segunda parte del libro — «Langston Hughes: An Afro-American View of the Conflict»- contamos con el estudio de Patricia San José, «The Writer as Notional Translator: Langston Hughes and His Transcultural Racial Interpretation of the Spanish Civil War» (pp. 23-43), y el de Andrew Samuel Walsh, «Empathy and Engagement in Translation: Langston Hughes's Versions of Lorca's Gypsy Ballads» (pp. 45-63), centrados en la figura del escritor y traductor estadounidense Langston Hughes, que trabajó como intérprete en la guerra civil, un pionero en la lucha en favor de los derechos civiles afroamericanos. E1 primero analiza el hecho de que, a lo largo de la guerra civil, Hughes actuó como traductor cultural analizando los movimientos políticos del momento y comparando la situación con lo que ocurría en su país: la lucha de la minoría afroamericana contra el racismo. Según San José, la producción literaria de Hughes revela la influencia combinada de las experiencias vividas en esta España, convirtiéndose así en un intermediario entre ambas.

Walsh, en el segundo estudio de esta sección, profundiza en el papel de Hughes como traductor del Romancero gitano, de Federico García Lorca, y el paralelismo que establece el estadounidense entre la marginación de la etnia gitana, rechazada por una sociedad opresora y menospreciada por la autoridad, y las experiencias similares que sufren sus compatriotas afroamericanos.

La tercera parte del volumen, «Interpreters and the Spanish Conflict», ahonda, en gran medida sobre el desconocido papel de los intérpretes internacionales durante la Guerra Civil Española a través del capítulo de Marcos Rodríguez Espinosa, titulado «Translating for the Legions of Babel: Spain 1936-1938» (pp. 67-87). El autor, que también ha analizado la presencia de mujeres intérpretes en los servicios médicos extranjeros en el artículo "The Forgotten Contribution of Women Translators in International Sanitary Units and Relief Organizations During and in the Aftermath of the Spanish Civil War", Current Trends in Translation Teaching and Learning E, 5 (pp. 348-394), examina en este trabajo el problema de comunicación que surge entre las distintas nacionalidades que componían los batallones de las Brigadas Internacionales y la búsqueda, en algunos casos, desesperada de mediadores lingüísticos capacitados para favorecer una comunicación fluida entre los distintos brigadistas. Resulta, asimismo, muy interesante la hostilidad y sospecha que algunos de estos traductores levantaban a causa de las diferencias ideológicas que convivían en el seno de las tropas leales a la República.

La cuarta sección del volumen, «Translation and Censorship During Franco's Dictatorship», se detiene en los años posteriores a la guerra civil. Pilar Godayol, Julia Lin Thompson y Rosa María Bautista-Cordero analizan, en sus respectivos capítulos, la censura franquista como sistema de control de ideologías subversivas a partir del análisis de los expedientes depositados en el Archivo General de la Administración (AGA) de Alcalá de Henares. Godayol, en este sentido, en «Depicting Censorship Under Franco's Dictatorship: Mary McCarthy, a Controversial Figure» ( $p p$. $9^{I-I I 2)}$, se sumerge en los efectos de la censura institucional en The Group, A Charmed Life y Birds of America, tres novelas de la estadounidense Mary McCarthy (1912-1989), que versaban principalmente sobre temas como el ateísmo, el feminismo, la libertad sexual, el control de la natalidad, etc.

Por otra parte, el estudio de Thompson titulado "Censorship and the Translation of Children's Literature: The Adventures of Huc- 
kleberry Finn in Franco's Spain (1939-I975)» (pp. II3-I42), prueba como también la literatura infantil era foco de censura y adoctrinamiento para la formación de jóvenes católicos en la España del Régimen a través de su análisis de las traducciones al español de Las aventuras de Huckleberry Finn, de Mark Twain, y descubre que, si bien en su cultura de origen no fue bien aceptada, para España se convirtió en un hito que asentó las bases de la ideología católica nacional.

Cierra este apartado, el trabajo de BautistaCordero "Adventures of a Young Man vs. Las aventuras de un joven: John Dos Passos's Fictional Enunciation of the Spanish Civil War in Franco's Spain» (pp. I43-160), en el que analiza el poder ejercido por los censores durante la dictadura franquista respecto de la traducción de obras literarias relacionadas con la guerra civil, sobre todo en la obra Dos Passos en el que el protagonista, Glenn Spotswood, pasa de abanderar rebeliones antifascistas a alistarse en el ejército de Franco. La traducción de esta novela, prohibida inicialmente en 1947 , fue autorizada en 1962 tras evidentes muestras de manipulación del texto para fines propagandísticos.

La quinta y última parte de esta obra, "Framing Translation and Memory of the Spanish Conflict», lo constituyen tres ensayos dedicados a la intersección que surge entre la traducción, el conflicto y memoria.

Kyra Kiertrys abre este apartado con «The Translation of Memory Through Television: El tiempo entre costuras and the Spanish Civil War» (pp. I63-I84) sobre la citada serie televisiva como forma de reflexión ante la perspectiva de la Guerra Civil desde la España del siglo xxi y, más allá, la percepción de esta a nivel internacional, gracias al impacto de Netflix. La traducción se ejecutaría, según Kiertys, a nivel intercultural, interlingual y de un medio de comunicación a otro (en este caso, del texto a la pantalla).
Desde una mirada humanista, la adaptación de la serie traducida al inglés consigue trasladar los traumas del pasado hacia un futuro mejor. Inês Espada Vieira, desde un perspectiva similar, en «Voices, Whispers and Silence: Translating Defeat and Building Memories of the Spanish Civil War and Francoism» (pp. 185-205), partiendo de la traducción al portugués de la novela Los girasoles ciegos, de Alberto Méndez, estudia el concepto de memoria transnacional (Brownlie, 20I7), esto es, una memoria que traspasa a otras culturas y países, y examina la forma en que se transmite una memoria forzosamente silenciada y el hecho de que lo que Assman (20Io) denominó «olvido dialógico» no implica un olvido efectivo. Por último, el volumen se cierra con el estudio de Pilar Cáceres, «Memory and Translation in La cabellera de la Shoá [The Hair of the Shoah] (2015) by Félix Grande» (pp. 207-226), en torno al único poema judío sobre el Holocausto de la poesía española del siglo xx. A través del mismo, Cáceres vincula estas experiencias con las traducciones del filósofo francés Jacques Derrida sobre la llamada hauntología.

La lectura de los diferentes trabajos reunidos en New Approaches to Translation, Conflict and Memory. Narratives of the Spanish Civil War and the Dictatorship supone una auténtica inmersión en la importancia de la memoria histórica y de su influencia en la traducción a otras lenguas y culturas. Estos especialistas en la materia han demostrado, a partir de sus exhaustivos estudios, que la traducción jamás podrá limitarse al campo del idioma y menos cuando se trata de un aspecto tan relevante para la ideología e historia de un país. Nos hallamos ante un trabajo colaborativo impecable que nos traslada a unos años de complejidad, miedos y represión de una forma seria, reflexiva y tremendamente acertada. 